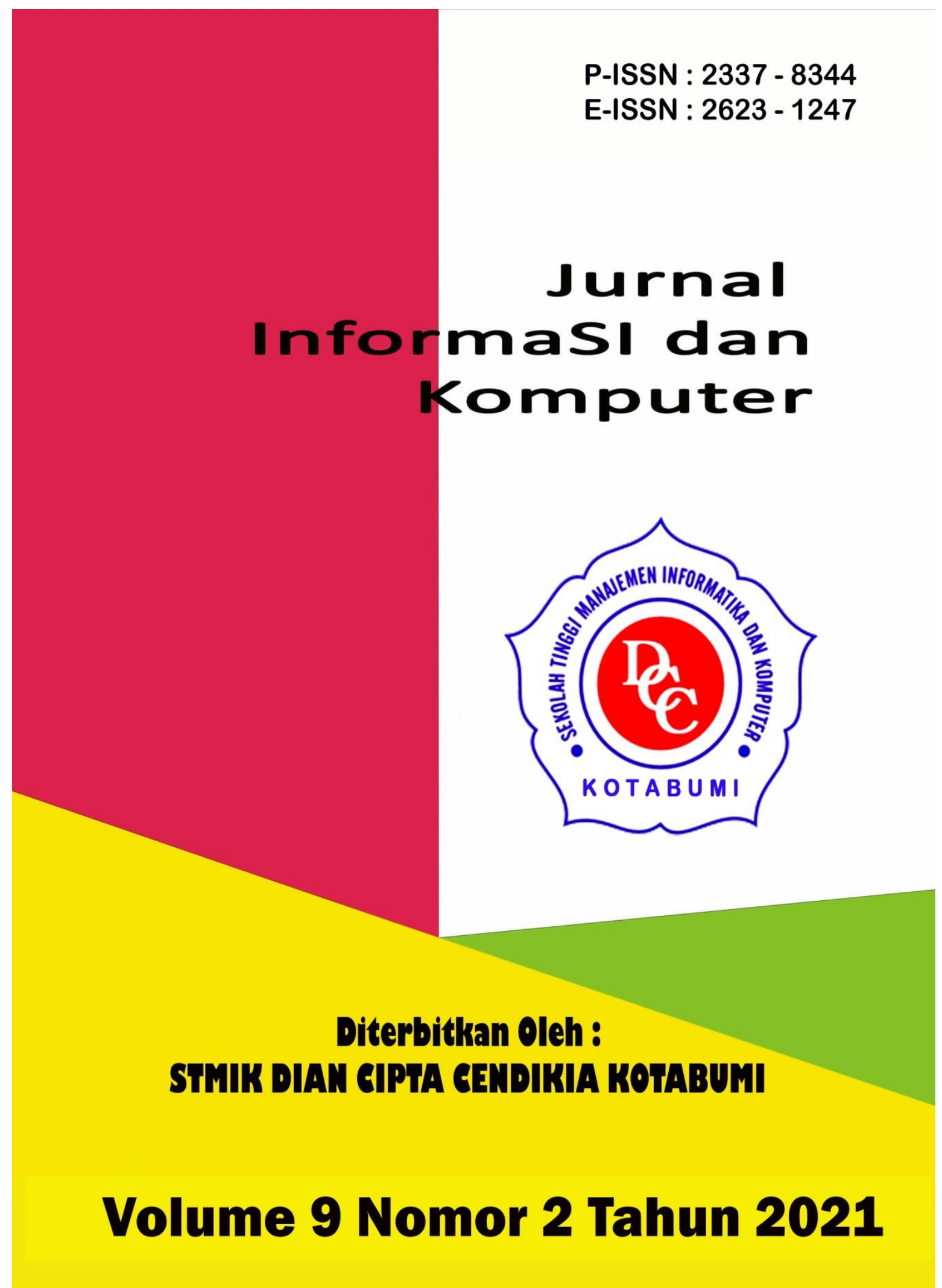


Penerbit

Lembaga Penelitian STMIK Dian Cipta Cendikia Kotabumi

Hak atas naskahh/tulisan tetap berada pada penulis, isi diluar tangung jawab penerbit dan Dewan Penyunting

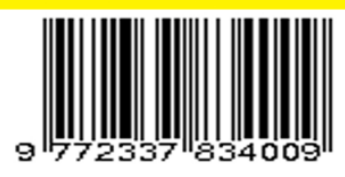




\section{PENGANTAR REDAKSI}

Puji syukur dipanjatkan kehadirat Tuhan Yang Maha Esa, atas karunia dan limpahan rahmatNYA jualah Jurnal Informasi dan komputer (JIK) STMIK Dian Cipta Cendikia Kotabumi ini dapat terwujud.Jurnal Informasi dan Komputer (JIK) yang terbit dua (2) kali dalam setahun ini merupakan suatu wadah untuk penyebar luasan hasil-hasil penelitian, studi pustaka, karya ilmiah yang berkaitan dengan Informasi dan Komputer khususnya bagi dosen-dosen STMIK Dian Cipta Cendikia Kotabumi serta umumnya para cendikiawan, praktisi, peneliti ilmu Informatika dan Komputer.

Harapan, dengan diterbitkannya Jurnal Informasi dan Komputer (JIK) ini sebagai salah satu bentuk sumbangan pemikiran dalam pengembangan ilmu informatika dan komputer yang berkaitan dengan kajian-kajian di bidang tekhnologi Informatik, Komunikasi Data dan Jaringan Komputer, perancangan dan Rekayasa Perangkat Lunak, serta ilmu-ilmu yang terkait dengan bidang Informasi dan Komputer lainnya.

Berkenaan dengan harapan tersebut, kepada para peneliti, dosen dan praktisi yang memiliki hasil-hasil penelitian, kajian pustaka, karya ilmiah dalam bidang tersebut diatas, dengan bangga redaksi Jurnal Informasi dan Komputer (JIK) menerima naskah ringkasan untuk dimuat pada jurnal Informasi dan Komputer (JIK) STMIK Dian Cipta Cendikia Kotabumi dengan berpedoman pada penulisan naskah jurnal sebagaimana dilampirkan pada halaman belakang (Bagian kulit dalam) buku jurnal ini.

Mutu dari suatu jurnal ilmiah tidak hanya ditentukan oleh para pengelolanya saja, tetapi para penulis dan pembaca jualah yang mempunyai peranan besar dalam meningkatkan mutu jurnal Informatika dan Komputer ini. Merujuk pada realita ini kamu sangat mengharapkan peran aktif dari peneliti untuk bersama-sama menjaga dan memelihara keberlangsungan dari jurnal Informasi dan Komputer STMIK Dian Cipta Cendikia Kotabumi ini. Yang juga tidak kalah pentingnya dari partisipasi tersebut diatas, adalah saran dan kritik yang membangun dari pembaca yang budiman agar kiranya dapat disampaikan langsung kepada redaksi JIK. Saran dan kritik yang membangun akan dijadikan masukan dan pertimbangan yang sangat berarti guna peningkatan mutu dan kualitas Jurnal Informasi dan Komputer STMIK Dian Cipta Cendikia Kotabumi.

Tak lupa diucapkan terima kasih yang tak terhingga atas perhatian dan kerjasama dari semua pihak yang tak dapat disebutkan satu persatu hingga dapat diterbitkan nya Jurnal Informasi dan Komputer (JIK) STMIK Dian Cipta Cendikia Kotabumi. Semoga apa yang telah diperbuat untuk kebaikan akan menjadi amal ibadah, amin.

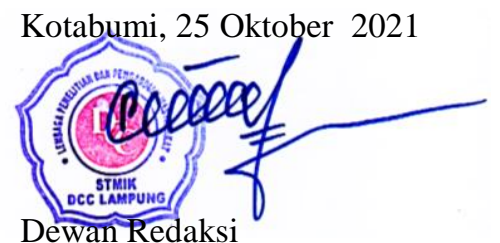




\section{JURNAL INFORMASI DAN KOMPUTER}

Volume 9 Nomor 2 Oktober 2021

Jurnal Informasi dan Komputer merupakan Sarana informasi ilmu pengetahuan, Tekhnologi dan Komunikasi yang berupa hasil penelitian, tulisan ilmiah, Ataupun studi pustaka. Jurnal ini terbit dua kali setahun pada bulan April dan Oktober. Berisi hasil penelitian ilmiah di bidang informatika yang bertujuan untuk menghubungkan adanya kesenjangan antar kemajuan teknologi dan hasil penelitian. Jurnal ini di terbitkan pertama kali pada tahun 2013.

Penanggung Jawab:

Ketua STMIK Dian Cipta Cendikia Kotabumi

Pembina:

Ketua STMIK Dian Cipta Cendikia Kotabumi Ketua Lembaga Penelitian STMIK Dian Cipta Cendikia Kotabumi

\section{Pimpinan Redaksi}

Dwi Marisa Efendi,.S.Kom.,M.Ti

Redaksi pelaksana

Rustam,.S.Kom,.M.Ti (STMIK Dian Cipta Cendikia Kotabumi)

Nurmayanti M.Kom (STMIK Dian Cipta Cendikia Kotabumi)

Sukatmi,.S.Kom., M.Kom (AMIK DCC Bandar Lampung)

Sampurna Dadi Riskiono,M.Kom (Universitas Teknokrat Indonesia)

Ifo Wahyu Pratama,S.Kom.,M.Ti(AMIK MASTER Lampung)

\section{Mitra Bestari}

Dr. RZ. ABDUL AZIZ, ST., MT (Institut Informatika dan Bisnis Darmajaya)

Dr. Dadang Sudrajat, S.Si, M.Kom (STMIK IKMI Cirebon)

Dr. Septafiansyah Dwi Putra, S.T., M.T (Politeknik Negeri Lampung)

Dr. Evi Grativiani, S.E., M.S.I (Universitas Sebelas Maret)

Rohmat Indra Borman ( Universitas Teknokrat Indonesia )

Ferry Wongso, S.KOm., M.Kom ( STMIK Darma Pala Riau)

Ferly Ardhy, S.Kom., M.Ti ( Universitas Aisyah Pringsewu )

Firmansyah, S.E., M.Si (STMIK Darma Pala Riau)
Amarudin (Universitas Teknokrat Indonesia)

Didi Susianto, S.T., M.Kom (AMIK Dian Cipta Cendika Bandar Lampung)

Alhibarsyah, St., M.Kom (STMIK Tunas

Bangsa Bandar Lampung)

Kemal Farouq Mauladi, S.Kom .M.Kom (Universitas Islam Lamongan)

Rima Mawarni, M.Kom ( STMIK Dian Cipta Cendikia Kotabumi)

Wira Jaya Hartono, S.Pd., M.Pd ( STMIK Darma Pala Riau)

Penerbit : STMIK Dian Cipta Cendikia Kotabumi Bekerja Sama Dengan LPPM STMIK Dian Cipta Cendikia Kotabumi.

\section{Alamat Redaksi/Penerbit:}

Jl. Negara No. 3 Candimas Kotabumi Lampung Utara

No Telpon/Fax 072423003

Email : 1ppm-stmik@dcc.ac.id 


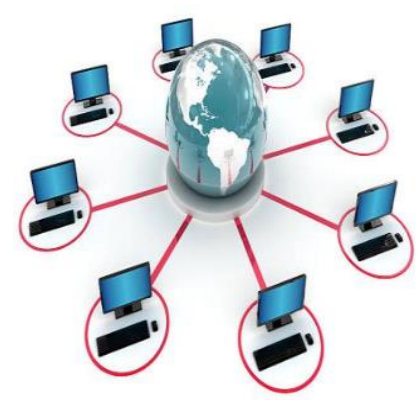

\section{JURNAL INFORMASI DAN KOMPUTER VOL. 9 NO. 2 THN. 2021}

\section{DAFTAR ISI}

Halaman

Sistem Informasi Akuntansi Persedian Barang Berbasis Web Pada Lembaga

Permasyarakatan Kelas II A Banceuy Bandung : "Kelompok Tani Desa Banjar Kertarahayu” Teuku Rian Hardiyansyah, Fatia Salsa Azzahra (Politeknik Piksi Ganesha Bandung ${ }^{1,2}$ ).

Penerapan Finite State Automata Pada Vending Machine Penjual Obat Non Resep

Dokter Dan Keperluan Medis

Eko Supriyanto $^{1}$, Angga Ardiansyah ${ }^{2}$, Frieyadie $^{3}$, Sri Rahayu ${ }^{4}$, Windu Gata ${ }^{5}$

(Universitas Nusa Mandiri ${ }^{12}$ )

Sistem Pendukung Keputusan Untuk Menentukan Kelayakan Pengajuan Sertifikasi Guru Dengan Metode Simple Additive Weighting (Studi Kasus : Ma Al Muhajirin Janti Jogoroto Jombang)

Budiman, umam baharudin, winarti

(Universitas Darul 'Ulum Jombang)

Perancangan Infrastruktur Domain Name Server Lokal Menggunakan Ubuntu Server 16.04

Pada PT. Xyz

Zaenal Mutaqin Subekti, Hendra Setiawan, Satria, Widia Murni Wijaya,

Aliy Hafiz, Warsudi

(STMIK Bani Saleh, Universitas Negeri Yogyakarta, AMIK Dian Cipta Cendikia,

STMIK MIC CIkarang)

Perancangan Sistem Informasi Idea Proposal (Ip) Berbasis Web Pada Pt. Paxel Algorita Unggul

Julian Murhan Sahputra, Indah Purnamasari

(Universitas Nusa Mandiri ${ }^{12}$ )

Sistem Pendukung Keputusan Untuk Menentukan Ekstrakurikuler Atletik

Berdasarkan Bakat Siswa Menggunakan Metode Profile Matching

Agnes Basuki, Petrus Sokibi, Tiara Eka Putri

(Universitas Catur Insan Cendekia)

Penerapan Algoritma K-Means Untuk Pengelompokan Usia Calon Penerima Vaksin

Di Kab. Ngawi

Irna Yuniarfi, Saifulloh

(Universitas PGRI Madiun ${ }^{12}$ )

System Penilaian Seleksi Calon Karyawan Baru Menggunakan Metode Simple Additive Weighting (SAW) Di PT.TNA

Anik Sri Wahyuningsih, Yudhi Firmansyah

(Universitas Panca Sakti Bekasi ) 
Perancangan Sistem Informasi Pembayaran SPP Menggunakan Framework Laravel Ichwan Habib Moudi

(Universitas Panca Sakti Bekasi)

Implementasi Algoritma K-Means Dan Algoritma Apriori Optimasi Kinerja Ecu

(Study Kasus Mobil Avanza Dan Xenia)

Sigit Mintoro' Asep Afandi

(STMIK Dian Cipta Cendikia Kotabumi)

Sistem Pakar Penyakit Buah Kakao Untuk Peningkatan Hasil Panen Kakao Menggunakan

Metode Case Base Reasoning (CBR) Berbasis Web Mobile

Aliy hafiz, Verawati

(AMIK Dian Cipta Cendikia,Bandar Lampung)

Penerapan Metode Rapid Application Develomment (RAD) Dalam Pengembangan

Sistem Pemesanan Menu Berbasis Android

Aris Baihaqi, Tumini

(Fakultas Sains dan Teknologi ${ }^{1,2}$ )

Rancang Bangun Sistem Informasi Geografis Pariwisata Di Lampung Timur

Sukatmi, Rexa Alfa Rizi

(AMIK DCC Bandar Lampung ${ }^{12}$ )

Implementasi Psak No. 45 Pada Proses Penyusunan Laporan Keuangan Menggunakan

M.S. Excel Dan Aplikasi Accurate Accouting Pada STMIK Bani Saleh

Marhakim, Willy Adam

(STMIK Bani Saleh ${ }^{12}$ )

Sistem Prediksi Harga KOPI LAMBAR ( Lampung Barat) Dengan Metode

Backpropagation, dan Double Exponential ( Studi Kasus BUMDES )

Supriyanto, Dwi marisa Efendi,Rhomadhon

(STMIK Dian Cipta cendikia Kotabumi ${ }^{1-}$ )

Sistem Informasi Pemasaran Produk Umkm Berbasis Web Pada Kecamatan Bumi

Nabung Lampung Tengah

Yuli Syafitri, Agus Prasetyo, Reni Astika

(AMIK Dian Cipta Cendikia Bandar Lampung)

Rancang Bangun Aplikasi Pembelajaran Aksara Lampung Berbasis Android

Ferly Ardhy, Hendra Syahrobi

(Universitas Aisyah Pringewu ${ }^{1,}$ STMIK Dian Cipta Cendikia ${ }^{2}$ )

Sistem Pakar Diagnosa Penyakit Kulit Pada Balita Menggunakan Metode Naïve

Bayes Dan Forward Chaining Studi Kasus Puskesmas Cempaka Sungkai Selatan

Sidik Rahmatullah, Rima Mawarni

(STMIK Dian Cipta Cendikia Kotabumi ${ }^{12}$ )

Rekayasa Perangkat Lunak Perhitungan Harga Pokok Produksi Metode

Full Costing Pada Umkm Mitra Cake Di Bandar Lampung

Pitrawati, Arif Sanjaya

(AMIK Dian Cipta Cendikia, Bandar Lampung) 
Rancang Bangun Sistem Ujian Online Menggunakan Algoritma Cosine Similarity

Berbasis Web

Haryono, Zaenal Mutaqin Subekti, Widiyawati, Hidayatullah

(STMIK Bani Saleh ${ }^{1234}$ )

Model Aplikasi Helpdesk Ticketing System Berbasis Web Menggunakan Metode Rad

Indra Permana

Pattern Recognition Tulisan Tangan Huruf Hijaiyah Menggunakan Metode

Convolutional Neural Network (CNN)

Mufassiril Abror, Nopiyanto

(Universitas Panca Sakti Bekasi ${ }^{12}$ )

Aplikasi Sistem Informasi Keuangan Berbasis Android Di Perumahan Taman

Karang Bahagia

Melda Ayulestari

(Universitas Panca Sakti Bekasi)

Audit Pelayanan Sistem Rujukan Online Puskesmas Menggunakan Framework COBIT 5.0

Nurmayanti, Merri Parida, Ngajiyanto, Ina Anzalna

(STMIK Dian Cipta Cendikia Kotabumi ${ }^{1234}$ )

Perancangan Sistem Informasi Pengolahan Data Nilai Siswa Berbasis Web

Erin Ermawati, Anik Sri Wahyuningsih

(Fakultas Sain dan Teknologi, Universitas Panca Sakti Bekasi ${ }^{12}$ )

Pengembangan Sistem Pelaporan Data Hasil Inspeksi Barang Berbasis Web

Siska Putriani

(Universitas Pancasakti Bekasi)

Penerapan Extreme Programming Dalam Perancangan Aplikasi Web Food Market

Tumini, Hilman Septiana

(Fakultas Sains dan Teknologi Universitas Panca Sakti Bekasi ${ }^{1,2}$ )

Sistem Pencarian Barang Berbasis Website Menggunakan Php Dan Mysql

Studi Kasus PT. Surya Technology Industri Sulaeman

(Universitas Panca Sakti Bekasi)

Implementasi Metode Prototype Pada Sistem Peminjaman Alat Kerja Berbasis Web

Di PT SK Metalindo

Ali Mulyanto, Arjun Gunawan

(Univeritas Panca Sakti Bekasi)

Aplikasi Tata Cara Wudhu Menggunakan Teknologi Augmented Reality

Sebagai Media Pembelajaran Di TK Al Fatih

Ahmad Yakub , Idarul Fadli

(Universitas Panca Sakti Bekasi ${ }^{12}$ )

Sistem Pakar Diagnosa Penyakit Ayam Petelur Menggunakan Metode Certainty Factor

Berbasis Web Mochammad

Taufiq Hidayat, Ali Mulyanto

(Universitas Panca Sakti Bekasi ${ }^{12}$ ) 
Penerapan Metode Prototyping Dalam Perhitungan Hasil Produksi Menggunakan

Arduino Uno R3 Dan Php Di PT. Indonesia Epson Industry

Amandha Aulia, Ajar Rohmanu

(Universitas Panca Sakti Bekasi ${ }^{12}$ )

System Pendukung Keputusan Penentuan Guru Teladan Dengan Metode Profile Matching

Hasbulloh, Agmawarnida

(Universitas Panca Sakti Bekasi ${ }^{1,2}$ )

Implementasi Waterfall Method Pada Aplikasi Buku Induk Siswa Berbasis Web

Idam Holid, Yogie Krisnayadi

(Universitas Panca Sakti ${ }^{12}$ )

Pengembangan Text To Speech Media Pembelajaran Untuk Pengenalan

Anggota Tubuh Manusia Kelas V Sekolah Dasar

Juwanda Saputra, Ali Mulianto

(Teknik Infomratika Fakulutas Sains dan Teknologi ${ }^{12}$ )

Perancangan Sistem Peminjaman Barang Berupa Aset Tetap Berbasis Web

Pada Lembaga Permasyarakatan Kelas II A Banceuy Bandung

Guntur Salasa Priambodo, Perwito, Candra Mecca Sufyana

(Politeknik Piksi Ganesha Bandung ${ }^{1,2,3}$ )

Metode Pemilihan Karyawan Terbaik Sebagai Penentu Goodwill Perguruan Tinggi

Dengan Menggunakan Metode Topsis (Studi Kasus Perguruan Tinggi Di Lampung Utara)

Dwi Sartika, Pakarti Riswanto

(STMIK Dian Cipta Cendikia Kotabumi)

Sistem Pendukung Keputusan Pemilihan Merek Smartphone Menggunakan

Metode Analytical Hierarchy Process (AHP)

Ade Kiki Fatmawati, Muhammad Sultan Raflie, Norma Yunita

(Universitas Nusa Mandiri ${ }^{123}$ )

Pattern Recognition Aksara Lampung Menggunakan Algoritma Neural Network

Metode Analytical Hierarchy Process (AHP)

Nopiyanto, Rahmadi

(Universitas Panca Sakti Bekasi) 


\title{
PERANCANGAN SISTEM INFORMASI IDEA PROPOSAL (IP) BERBASIS WEB PADA PT. PAXEL ALGORITA UNGGUL
}

\author{
Julian Murhan Sahputra ${ }^{1}$, Indah Purnamasari ${ }^{2}$ \\ Universitas Nusa Mandiri ${ }^{12}$ \\ Jl. Kramat Raya No.18, Senen, Kota Jakarta Pusat, Indonesia \\ E-mail : Julianmurhans@ gmail.com¹, indah.ihi@ nusamandiri.ac.id ${ }^{2}$
}

\begin{abstract}
ABSTRAK
Dalam Perkembangan ilmu pengetahuan, manusia sebenarnya cenderung bergerak maju. Khususnya di bidang teknologi, kehadiran internet dan kemudahan yang diberikan adalah tolak ukur suatu negara. Karena alasan inilah penulis ingin memanfaatkan teknologi tersebut untuk digunakan di masyarakat. Mengembangkan aplikasi berbasis web dan sudah responsive yang dapat dibuka menggunakan smartphone atau layar kecil untuk perusahaan adalah tujuan penulis. dimana hasil Inovasi karyawan tersebut bisa langsung diolah oleh divisi yang membutuhkan kapan pun dan dimanapun selama terhubung dengan internet. Penulis merancang sistem informasi ini dimana pembangunannya menggunakan bahasa pemrograman php dan databasenya menggunakan mysqli. Penulis juga menggunakan framework dan plugin. Framework yang digunakan untuk php yaitu codeigniter versi 3.17 dan untuk css menggunakan bootstrap versi 3.3.7. Dalam sistem informasi yang penulis buat terbagi dalam 3 aktor atau pengguna yang terlibat, yaitu HR-PX, Karyawan, dan Kepala Seksi, dimana jika sebelumnya untuk penginputa ide karyawan, karyawan harus menulis ide nya pada sebuah form manual yg di tulis tangan atau di cetak kertas, dan karyawan mengajukan persetujuan ke kepala seksi dan HR secara manual dan membutuhkan waktu yang cukup lama, dan bagi kepala seksi dan HR pun untuk melakukan penilaian masih manual dan sering kali terjadi kekeliruan data atau hilangnya form kertas, maka dengan adanya system ini HR-PX sebagai pengelola sistem dimana dia yang membuat master data mulai dari data karyawan, data seksi , data kepala seksi sampai dengan data ide karyawan dan mengelola sistem tersebut. selanjutnya Kepala Seksi yang dapat memberikan nilai dari hasil ide karyawan selain itu kepala seksi juga dapat memberikan catatan untuk tujuan pengembangan atau inovasi pada ide berikutnya dalam proses pengembangan . Dan yang terakhir Karyawan, untuk menginput ide yang telah dibuatnya, dan juga dapat melihat rekap dari ide yang telah dibuatnya selama bekerja, selain itu karyawan juga dapat melihat nilai atau hasil ide inovasinya selama bekerja.
\end{abstract}

Kata kunci : Sistem Informasi Idea Proposal (IP), Berbasis Web.

\section{ABSTRACTS}

In the development of science, humans actually tend to move forward. Especially in the field of technology, the presence of the internet and the convenience it provides are the benchmarks of a country. For this reason, the author wants to use this technology for use in society. Developing web-based and responsive applications that can be opened using smartphones or small screens for companies is the author's goal. where the results of employee innovation can be directly processed by the division that needs it anytime and anywhere as long as it is connected to the internet. The author designed this information system where the construction uses the php programming language and the database uses mysqli. The author also uses frameworks and plugins. The framework used for php is codeigniter version 3.17 and for css using bootstrap version 3.3.7. In the information system that the author made, there are 3 actors or users involved, namely HR-PX, Employees, and Section Heads, where previously for inputting employee ideas, employees must write their ideas on a manual form that is handwritten or printed. paper, and employees submit approval to the section head and HR manually and it takes quite a long time, and even for section heads and HR to carry out an assessment it is still manual and there are often data errors or loss of paper forms, so with this system HR-PX is the system manager where he creates master data from employee data, section data, section head data to employee idea data and manages the system. Furthermore, the Section Head who can provide value from the results of the employee's ideas besides the 
section head can also provide notes for the purpose of development or innovation on the next idea in the development process. And lastly, employees, to input the ideas they have made, and can also see a recap of the ideas they have made while working, besides that employees can also see the value or results of their innovation ideas while working.

Keywords: Innovation Idea Proposal System (IP), Web Based.

\section{PENDAhULUAN}

Seiring dengan pesatnya kemajuan Teknologi Informasi , informasi merupakan suatu hal yang penting dalam menjalankan suatu pekerjaan dan kegiatan usaha. Teknologi informasi menjadi salah satu sarana yang amat penting dalam menunjang suatu perusahaan, instansi dan departemen baik Swasta maupun negeri pada skala kecil, sedang, maupun besar, Diharapkan dengan informasi dapat mempermudah pekerjaan serta tujuan agar tercapai dengan maksimal. Menurut DR. Richardus Eko Indrajit "sistem informasi dan teknologi informasi tidak hanya berfungsi sebagai sarana pendukung untuk meningkatkan kinerja perusahaan dari waktu ke waktu, tetapi lebih jauh lagi telah menjadi senjata utama dalam bersaing." [1].

Informasi adalah unsur yang menghubungkan fungsi - fungsi manajemen diantaranya terdiri dari perencanaan, pengendalian, dan pengoprasian perusahaan. Tanpa informasi sebuah perusahaan tidak akan dapat melaksanakan kegiatan operasional perusahaan dengan baik. Karena itu untuk mendukung pelaksanaan informasi perusahaan, instansi dan departemen yang baik dan teratur, maka dibutuhkan sebuah sistem yang terkomputerisasi. Salah satu sistem yang diperlukan oleh perusahaan yaitu informasi Idea Proposal.

Divisi PX - PR (People Experience - People Relation) harus mencatat dan menilai setiap kali ada karyawan yang ingin mengajukan form Idea Proposal.yaitu harus mencatat NIK karyawan,nama, bagian, dan posisi karyawan serta harus mencatat jenis ide yang diajukan dan mengecek apakah ada duplikasi ide yang pernah dibuat sebelumnya oleh karyawan lain. Hal ini membutuhkan ketelitian dari bagian PX - PR (People Experience - People Relation) selain itu divisi PX juga membutuhkan 3 orang anak PKL untuk membantu proses penginputan dan pengecekan form Idea Proposal yang diajukan oleh karyawan
Agar dalam setiap laporan dan penilaian tidak terjadi kesalahan yang berakibat bahwa ide yang sudah dibuat oleh karyawan ternyata salah penilaian dan salah NIK, sehingga menyebabkan karyawan yang membuat ide tidak mendapat point dari ide yang telah dibuatnya untuk penilaian kinerja karyawan. Menurut Rerry Tiqwani dan Dewie Tri Wijayanti pada Jurnal Ilmu Manajemen "Pada dasarnya semua perusahaan pasti akan melakukan penilaian kinerja kepada karyawannya, itu semua dilakukan yang bertujuan sebagai bahan evaluasi perusahaan agar kinerja yang belom optimal dapat diperbaiki menjadi yang optimal. Kinerja karyawan yang baik akan berdampak pada perusahaan, apabila kinerja karyawan baik maka akan berdampak baik pula kepada perusahaan." [2]. Selain itu setiap harinya karyawan pasti ingin lebih mudah untuk membuat ide-ide untuk mempermudah pekerjaannya, terlebih ide-ide yang mereka buat itu berguna sebagai tambahan penilaian untuk evaluasi kontrak dan evaluasi penilaian untuk kenaikan gaji mereka.

Demi sebuah penilaian karyawan rela menulis di sebuah form kertas dan meminta approval terkait ide yang mereka ajukan ke pimpinan mereka, walaupun belum tentu ketika meminta approval, pimpinan mereka ada di meja kerjanya, karena sering kali pimpinan mereka ada meeting sehingga sulit untuk ditemui, Oleh sebab itu, dibutuhkan keikutsertaan teknologi infomasi dalam bentuk web dengan menggunakan jaringan internal untuk mempermudah hal tersebut.

\section{METODE PENELITIAN}

\section{Teknik Pengumpulan Data}

\section{a. Observasi}

Penulis melakukan pengamatan di perusahaan dan mempelajari dari berbagai situs tentang sistem innovation Proposal atau semacamnya dari referensi perusahaan lain maupun dari internet . kegiataan ini dilaksanakan untuk mengetahui proses/prosedur dari kegiatan 
tersebut.

\section{b. Wawancara}

Wawancara dilaksanakan dengan melakukan pembicaraan seputar tanya jawab bersama karyawan perusahaan khususnya dibagian PX PR (People Experience - People Relation) guna mendapatkan informasi penting yang berkaitan dengan proses Penginputan maupun penilaian idea proposal pada PT. Paxel Algorita Unggul

\section{c. Studi Pustaka}

Melakukan studi kepustakaan dengan mengumpulkan data dan informasi mengenai prosedur sistem yang telah ada pada PT. Paxel Algorita Unggul, analisa perancangan sistem berorientasi objek dan bahasa pemrograman yang dapat digunakan sebagai acuan pembahasan dalam masalah ini.

Model Pengembangan Sistem (Waterfall)

\section{d. Analisa Kebutuhan Sistem}

Untuk membangun sebuah sistem dibutuhkan adanya masukan berupa data yang nantinya akan diproses oleh sistem sehingga sistem dapat memberikan informasi yang bermanfaat kepada penggunanya. Kebutuhan data dan informasi untuk sistem informasi Idea Proposal Pada PT. Paxel Algorita Unggul.

Data-data yang diperlukan antara lain :

1. Data Perusahaan

2. Data Karyawan

3. Data Ide

4. Data Penilaian

\section{e. Desain}

Desain dan pembuatan program berkonsentrasi pada bagaimana sistem dibangun untuk memenuhi kebutuhan pada fase analisis, membangun perangkat lunak untuk mendukung sistem dengan menggunakan software architecture (UML) dan user interface (PHP, HTML, VS CODE, JavaScript, XAMPP, dan MySQL) serta model relasional database yang di gunakan sehingga mempermudah interaksi antara sistem dengan pengguna.

\section{f. Code Generation}

Dalam penulisan skripsi ini penulis menggunakan bahasa pemrograman PHP dan MYSQL untuk pengolahan database yang merupakan sebuah produk open source, dan , CSS Bootstrap.

\section{g. Testing}

Uji coba fungsi mengaplikasikan teknik blackbox, metode uji coba blackbox memfokuskan pada keperluan fungsional dari software. Karena itu uji coba blackbox memungkinkan pengembang software untuk membuat himpunan kondisi input yang akan melatih seluruh syarat-syarat fungsional suatu program.

\section{h. Support}

Mendefinisikan upaya pengembangan terhadap sistem yang sedang dibuat dalam mengantisipasi perkembangan maupun perubahan sistem yang bersangkutan terkait dengan hardware dan software yang akan digunakan.

\section{HASIL DAN PEMBAHASAN}

\section{Analisa Kebutuhan}

Berdasarkan analisa yang sudah dilakukan, penulis melihat masih adanya kekurangan pada sistem berjalan di PT. Paxel Algorita Unggul yaitu belum menggunakan sistem yang terkomputerisasi secara optimal, sehingga dapat mengakibatkan beberapa kegiatan manual yang cukup memakan waktu. Dalam hal ini ada beberapa dokumen yang dicetak, Namun jika dibuat dalam sebuah sistem hasil olahan data yang diperlukan dapat diperlihatkan langsung tanpa harus mencetak berkas tersebut, data yang dimaksud juga sudah masuk kedalam sebuah database yang jika suatu saat dibutuhkan dapat dipanggil oleh sistem.

Oleh karena itu sistem informasi dibutuhkan untuk mempermudah Serta mempercepat proses transaksi dan pengolahan data pada perusahaan. Dalam proses pengolahan data ini terdapat dua pengguna yang saling berinteraksi dalam sebuah sistem usulan ini, yaitu User (Pimpinan Seksi),Admin (HR-PX), dan karyawan Masingmasing pengguna mempunyai kebutuhan informasi dan hak akses yang berbeda dalam sistem. Berikut spesifikasi kebutuhan dari sistem Idea Proposal pada PT. Paxel Algorita Unggul: 


\section{Admin (HR-PX)}

Dalam Sistem Informasi Idea Proposal ini. Admin melakukan login, bertanggung jawab dalam mengelola kebutuhan sistem dan administrator, seperti data Penilaian, Kategori Ide, Karyawan, Approval ide dan cetak laporan.

\section{User (Pimpinan Seksi)}

Dalam kebutuhan user terdiri dari Pimpinan Seksi yang akan Melakukan Login, approval atas ide yang diajukan oleh karyawannya dan memastikan ide tersebut berjalan dilapangan, serta dapat memberikan penilaian untuk ide karyawan. User juga bisa melihat halaman Ide untuk memastikan kembali bahwa ide yang dibuat oleh karyawannya sudah di approve dan diberikan penilaian, Selain itu user juga dapat melihat rekapan seluruh ide yang telah dibuat oleh karyawan pada seksi yang dipegang oleh pimpinan tersebut

\section{Karyawan}

Dalam kebutuhan halaman ini karyawan bisa melakukan login dengan NRP (Nomor Registrasi Pegawai) dan password yang telah diberikan. Karyawan juga dapat menginput ide yang telah dibuatnya dilapangan, Karyawan mengupload Foto hasil idenya dilapangan, dan Karyawan dapat melihat history Ide yang pernah dibuat selama bekerja.

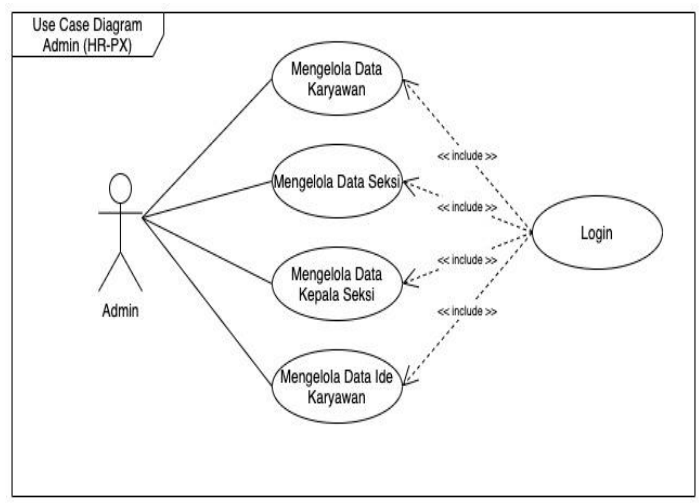

Gambar 1. Use Case Diagram Admin

Berdasarkan dari gambar 1 dapat diketahui aktivitas apa saja yang dapat dilakukan oleh Admin / HR-PX. Admin dapat mengedit dan mengelolaData Karyawan, Data Seksi, Data Kepala Seksi, dan Data Ide
Karyawan Sistem akan menampilkan halaman untuk Mengelola Data Ide Karyawan.

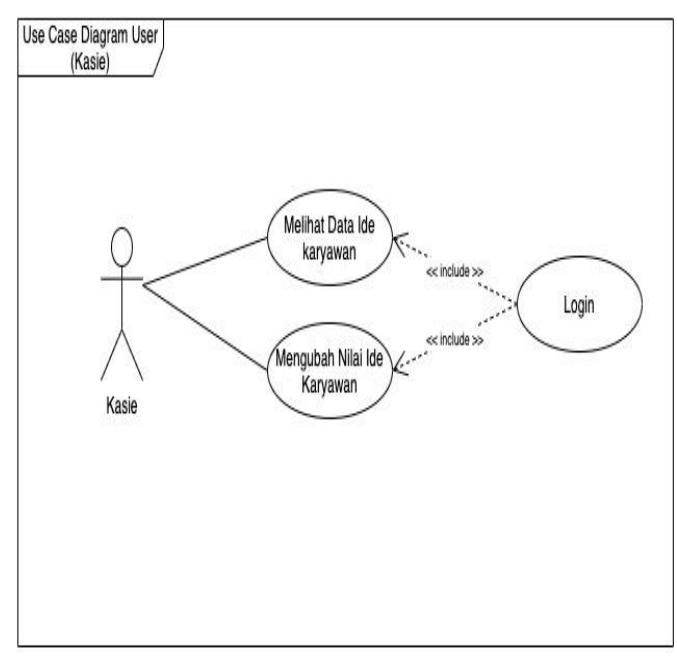

Gambar 2. Use Case Diagram Kasie

Berdasarkan dari gambar 2 dapat diketahui aktivitas apa saja yang dapat dilakukan oleh User / Kasie. Kasie dapat Melihat Ide Karyawan dan Mengubah Nilai Ide Karyawan.

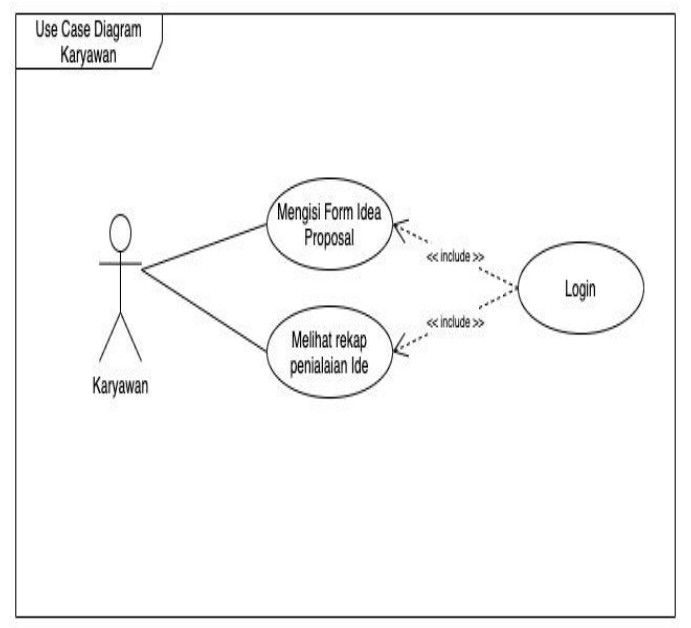

Gambar 3. Use Case Diagram Karyawan

Berdasarkan dari gambar 3 dapat diketahui aktivitas apa saja yang dapat dilakukan oleh Karyawan. Karyawan dapat Mengisi Form Idea Proposal dan Melihat Rekap Penilaian Ide Karyawan. 


\section{Perancangan Perangkat Lunak}

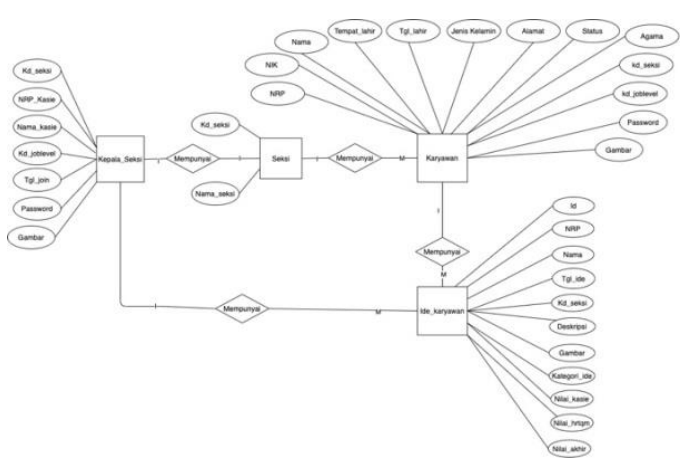

Gambar 4. Entity Relationship Diagram

Pada gambar 4 menampilkan rancangan entity relationship diagram pada sistem informasi pemesanan unit property

\section{User Interface}

Berikut Tampilan Untuk Login User

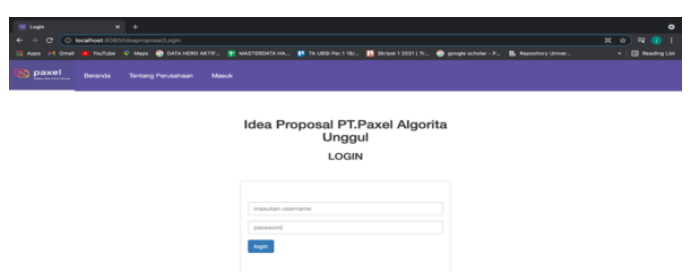

Gambar 5. Tampilan Login
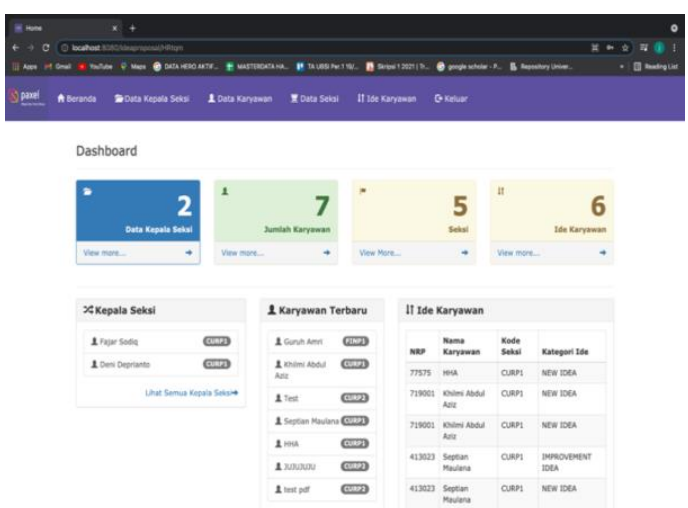

Gambar 6. Tampilan Dashboard HR-PX

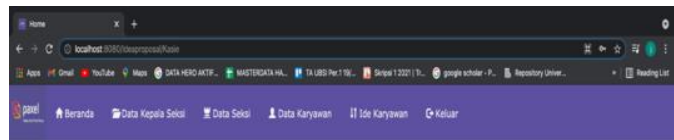

Dashboard

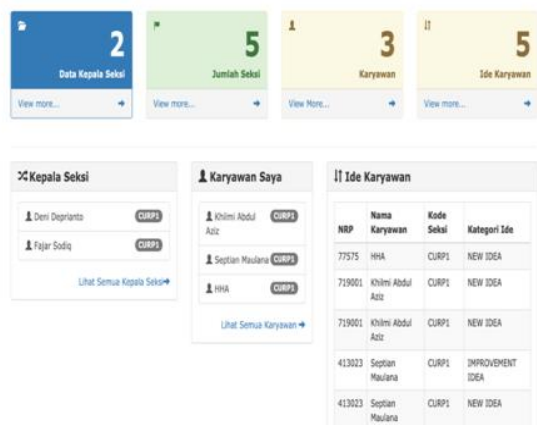

Gambar 7. Tampilan Dashboard Kepala Seksi

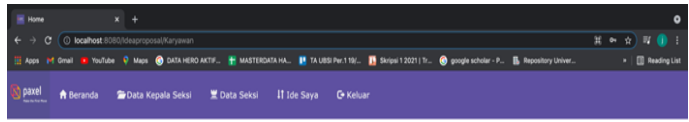

Dashboard

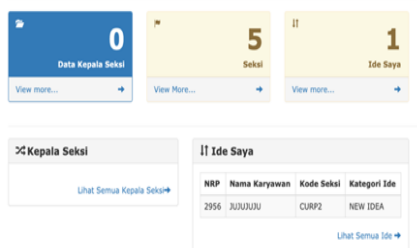

Gambar 8. Tampilan Dashboard Karyawan

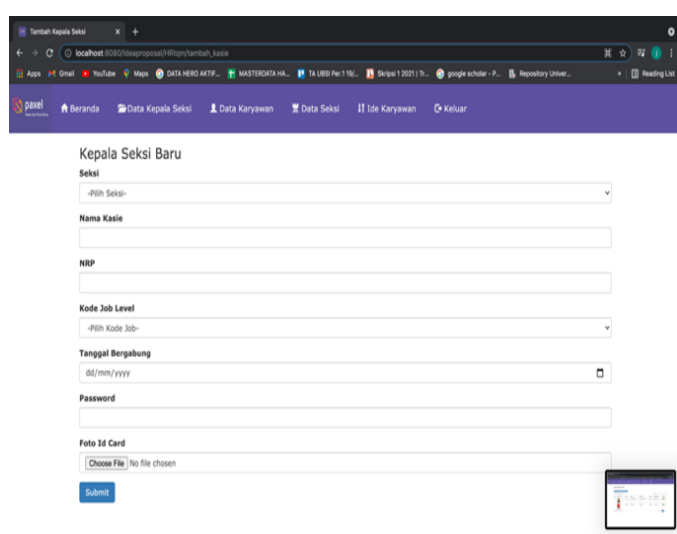

Gambar 9. Tampilan HR-PX Tambah Kepala Seksi 


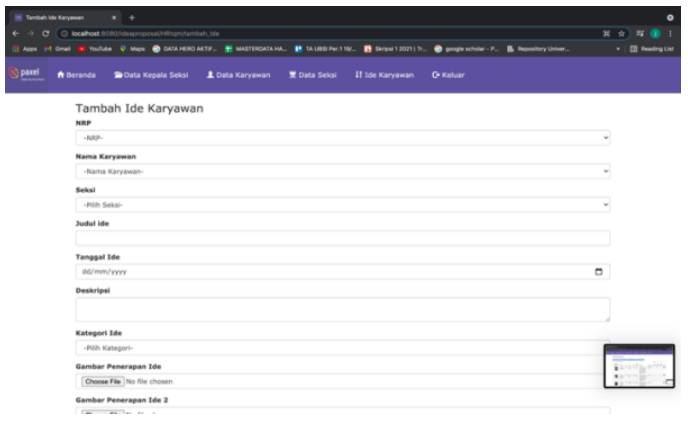

Gambar 10. Tampilan Tambah Ide Karyawan

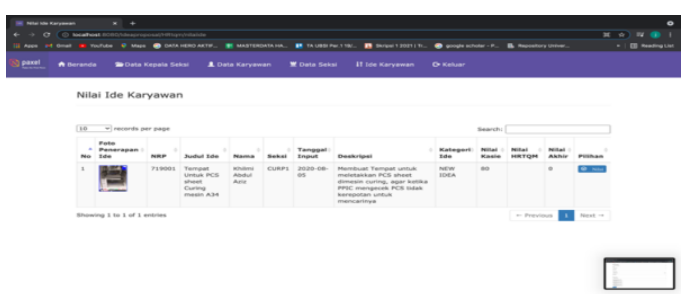

Gambar 11 . Tampilan Nilai Ide Karyawan

\section{KESIMPULAN}

Setelah mengamati sistem pengelolaan Idea Proposal di perusahaan. Penulis juga sudah mencoba memberikan solusi untuk meningkatkan sistem informasi yang ada. Sistem Informasi yang dimaksudkan adalah di bidang pengelolaan untuk karyawan memasukkan ide dan mengelola nilai. Maka penulis dapat menarik kesimpulan dan saran sebagai berikut :

Setelah merancang Sistem Informasi Idea Proposal pada PT. Paxel Algorita Unggul yang dibuat dalam bentuk aplikasi web, penulis mengambil kesimpulan sebagai berikut :

1. Diharapkan dengan diterapkannya Sistem Informasi Idea Proposal ini team HR-PX dan kepala seksi dapat dengan mudah melakukan pengelolaan nilai dengan tidak melakukan penumpukan dokumen / form berbentuk kertas yang sering kali terselip.

2. Diharapkan dengan diterapkannya Sistem Informasi Idea Proposal ini pencarian data karyawan dan kepala seksi dapat menjadi lebih efektif. karyawan tidak perlu harus ke $P X$ admin atau kepala seksi tidak perlu lagi tidak perlu $P X$ admin untuk memperoleh data yang diinginkan karena data sudah dalam tersimpan di Database Server dan dapat dengan mudah diakses melalui internet.

3. Diharapkan dengan diterapkannya Sistem Informasi Idea Proposal ini Karyawan, Kepala Seksi atau HR PX dengan mudah mendapatkan informasi laporan hasil nilai dan rekapan ide karyawan.

\section{DAFTAR PUSTAKA}

[1] R. E. Indrajit, "Manajemen sistem informasi dan teknologi informasi," Jakarta PT Elex Media Komputindo, 2000.

[2] R. Tiqwani, D. Tri, and W. W. J. Manajemen, "Pengaruh Kepemimpinan Dan Budaya Inovatif Terhadap Kinerja Karyawan," J. Ilmu Manaj., vol. 2, 2014.

[3] A. Kristanto, Perancangan Sistem Informasi dan Aplikasinya. Yogyakarta: GAVA MEDIA, 2018.

[4] A. Kristanto, Perancangan Sistem Informasi dan Aplikasinya. Yogyakarta: GAVA MEDIA, 2018.

[5] R. A. Sukamto and M. Shalahuddin, "Modul pembelajaran rekayasa perangkat lunak (terstruktur dan berorientasi objek)," Bandung Modul., 2013.

S. M. Lasmaya, "Pengaruh Sistem Informasi SDM, Kompetensi dan Disiplin Kerja Terhadap Kinerja Karyawan,” J. Ekon. Bisnis Entrep., vol. 10, no. 1, pp. 25-43, 2016.

[6] Y. Yudhanto and A. Purbayu, Toko Online Dengan PHP dan MySQL. Jakarta: PT Elex Media Komputindo, 2014.

[7] B. I. Sidik and I. H. I. M. E. Pohan, Pemrograman WEB dengan HTML. Bandung: Informatika Bandung, 2014.

[8] D. Setiawan, BUKU SAKTI PEMOGRAMAN WEB: HTML, CSS, $P H P$, MySQL \& Javascript. Yogyakarta: START UP, 2017.

[9] P. Hidayatullah and K. J. Kawistara, PEMROGRAMAN WEB, Revisi. Bandung: Informatika Bandung, 2017. 